\title{
Evaluasi Pelaksanaan Credit Risk Management pada PT BPR X
}

\author{
Putri, A. A., Hakim M. S., dan Bramanti, G. W \\ Departemen Manajemen Bisnis, Fakultas Bisnis dan Manajemen Teknologi, \\ Institut Teknologi Sepuluh Nopember (ITS) \\ e-mail:aninditaamaliap@gmail.com
}

\begin{abstract}
Abstrak - Lembaga keuangan Bank Perkreditan Rakyat (BPR) memiliki peran yang penting bagi keberlanjutan ekonomi suatu negara terutama dalam bidang kredit. Kredit berarti memberikan dana yang dimiliki untuk dipinjamkan kepada orang lain, yang mana akan timbul risiko yang besar apabila tidak dikelola dengan baik. Besar kecilnya risiko kredit, dapat ditunjukkan dengan rasio NPL. Kenaikan rasio NPL menjadi pertanda bahwa pengelolaan manajemen risiko kredit bank tersebut mengalami penurunan. Hal ini menyebabkan pelaksanaan manajemen risiko kredit bagi BPR sangatlah penting. Sehingga tujuan penelitian ini adalah menganalisis penerapan prinsip-prinsip manajemen risiko kredit Bank of International Settlements pada PT BPR X. Penelitian ini menggunakan desain riset eksploratif dengan metode kualitatif. Pengumpulan data penelitian dilakukan dengan cara wawancara kepada 4 responden selaku pimpinan BPR X dan observasi terhadap pelaksanaan manajemen risiko kredit di PT BPR X. Hasil penelitian ini menunjukkan bahwa BPR X tidak memenuhi 3 dari 17 prinsip manajemen risiko kredit Bank of International Settlements. Ketiga prinsip yang tidak memenuhi tersebut adalah prinsip ke-5, prinsip ke-10, dan prinsip ke-13.
\end{abstract}

Kata Kunci-Kredit, Manajemen Risiko, Prinsip Manajemen Risiko Kredit Bank of International Settlements, Risiko Kredit.

\section{PENDAHULUAN}

$\mathrm{L}$ EMBAGA keuangan terutama bank memiliki peran sebagai penghimpun dana dari masyarakat dalam bentuk simpanan dan penyalur dana masyarakat dalam bentuk kredit. Dalam lingkup yang lebih sempit Bank Perkreditan Rakyat (BPR) lebih di ditujukan sebagai institusi keuangan mikro. Di Indonesia perkembangan BPR cukup pesat, hingga mencapai 1.633 BPR [1].

Beberapa isu strategis BPR saat ini yaitu pertama fakta masih besarnya kebutuhan masyarakat terhadap kredit kecil dan mikro, kedua yaitu tekanan persaingan yang semakin kuat antar BPR maupun dengan lembaga keuangan lainnya dan ketiga yaitu meningkatnya jumlah BPR dengan kinerja yang kurang baik [2]. Terkait isu ketiga berakibat pada jumlah BPR yang menurun (bi.go.id). Sebagian besar BPR yang dicabut izin usahanya disebabkan oleh kegiatan fraud. Fraud terjadi salah satunya karena BPR tidak melaksanakan manajemen risiko yang baik [3].

Peraturan terkait penerapan manajemen risiko BPR telah diatur oleh Otoritas Jasa Keuangan (OJK) pada Peraturan Otoritas Jasa Keuangan Nomor 13/POJK.03/2015. Pada Pasal 3 ayat 1 POJK terdapat enam jenis risiko, salah satunya yaitu risiko kredit. Risiko kredit adalah ketidakmampuan pengguna kredit untuk membayar kembali pinjaman yang diberikan sehingga muncul kredit macet atau bad debt. Kredit macet adalah kredit yang tidak memenuhi kriteria lancar, kurang lancar, dan diragukan. Kredit macet dapat terjadi salah satunya sebagai akibat dari analisis pemberian kredit yang kurang baik. Risiko kredit dapat ditemukan, salah satunya, pada laporan keuangan bank. Sumber risiko kredit pada bank dapat dilihat di laporan keuangan pada bagian kredit tidak lancar (non performing loan).

Pada pertengahan tahun 2015 terjadi kenaikan NPL yang cukup signifikan yang juga mempengaruhi NPL pada bankbank termasuk BPR [4]. Dimana NPL adalah salah satu penentu risiko kredit suatu BPR. Rasio NPL PT BPR X mengalami peningkatan yang signifikan selama 5 tahun terakhir. Kenaikan NPL BPR X sebesar lebih dari 2 persen yang mana hal ini tergolong tinggi. Seperti pada bank-bank lain, diduga kenaikan NPL BPR X juga dikarenakan adanya perlambatan bisnis di beberapa sektor. Namun tidak menutup kemungkinan bahwa terjadi kekurangan dalam pelaksanaan manajemen risiko kreditnya.

Hingga saat ini PT BPR X memiliki 1800 lebih nasabah dengan sektor ekonomi mayoritas di bidang pertanian. PT BPR X berlokasi di barat daya Kabupaten Jember sehingga sebagian besar nasabah berasal dari daerah Kabupaten Jember dan Kabupaten Lumajang. Pada aspek perkembangan jumlah aset kabupaten Jember menempati urutan keenam dengan kontribusi sebesar 4,8\% dari total aset Jawa Timur sebanyak 12.037.411.063 (dalam ribuan rupiah). Sedangankan dilihat dari perkembangan jumlah BPR, Kabupaten Jember menempati urutan ketiga dengan jumlah BPR sebanyak 24 dari 321 BPR di Jawa Timur. Dari beberapa data statistik seputar BPR, dapat dilihat bahwa perkembangan BPR dan kredit di Kabupaten Jember cukup berpengaruh di wilayah provinsi Jawa Timur sehingga objek amatan yang dipilih yaitu salah satu BPR di Kabupaten Jember.

Manajemen risiko kredit bagi perbankan menggunakan kerangka pengukuran risiko kredit Basel Committee on Banking Supervision (BCBS) yang dibentuk oleh Bank of International Settlements (BIS). Terdapat 17 prinsip manajemen risiko kredit yang dibuat namun di Indonesia hanya diterapkan pada bank umum saja sedangkan pada BPR sistem ini tidak berlaku [5]. Maka dari itu peneliti ingin menganalisis bagaimana penerapan prinsip-prinsip manajemen risiko kredit bagi BPR mengacu pada BIS. Objek amatan yang digunakan oleh peneliti adalah PT BPR $X$. PT BPR X mengalami kenaikan NPL yang membuat BPR harus lebih waspada terhadap risiko kreditnya

\section{TINJAUAN PUSTAKA}

\section{A. Manajemen Risiko Kredit}

Manajemen risiko menurut pendefinisian Bank Indonesia dan OJK memiliki makna serangkaian metodologi dan prosedur yang digunakan untuk mengidentifikasi, mengukur, memantau, dan mengendalikan risiko yang 
Tabel 1

Daftar Responden

\begin{tabular}{lcc}
\hline \hline \multicolumn{1}{c}{ Jabatan } & $\begin{array}{c}\text { Usia } \\
\text { (tahun) }\end{array}$ & $\begin{array}{c}\text { Lama Bekerja } \\
\text { (tahun) }\end{array}$ \\
\hline Direktur utama & 49 & 4 \\
PE Kabag Kredit & 49 & 27 \\
PE Manajemen Risiko dan Kepatuhan & 33 & 10 \\
PE Kabag Operasional dan UKK & 35 & 4 \\
\hline \hline
\end{tabular}

timbul dari seluruh kegiatan usaha bank. Clough dan Sears [6] mendefinisikan manajemen risiko sebagai suatu pendekatan yang komprehensif untuk menangani kejadiankejadian yang dapat menimbulkan suatu kerugian.

\section{B. Resiko Kredit}

Risiko kredit adalah kemungkinan hilangnya uang dikarenakan ketidakmampuan, ketidakinginan, atau bukan waktunya dari pihak lain atau pihak ketiga untuk membayar kewajiban keuangannya [7]. Untuk mencegah risiko kredit dibutuhkan analisis kredit yang memadai. Analisis kredit adalah kegiatan pemeriksaan, penelitian, dan analisis terhadap kelengkapan, keabsahan, dan kelayakan berkas/surat/data permohonan kredit calon debitur hingga dikeluarkannya suatu keputusan apakah kredit tersebut diterima atau ditolak [8].

\section{METODOLOGI PENELITIAN}

\section{A. Jenis Data}

Data yang digunakan dalam penelitian ini adalah data primer yaitu hasil wawancara yang dilakukan kepada responden. Data primer diperoleh dari wawancara kepada direksi beserta manajer PT BPR X. Data yang dibutuhkan meliputi bagaimana penerapan manajemen risiko yang telah dilaksankan oleh BPR.

\section{B. Pengumpulan Data}

Penelitian dilakukan dengan menggunakan metode observasi dan wawancara mendalam secara semi-struktur. Tujuan dilakukannya observasi adalah agar peneliti dapat mengamati aktivitas-aktivitas yang berlangsung selama wawancara maupun selama penerapan manajemen risiko di BPR X. Penelitian dilakukan pada bulan Februari 2017 hingga Juli 2017. Penelitian dilakukan di kantor PT BPR X yang berlokasi di Kabupaten Jember, Jawa Timur. Desain penelitian yang digunakan yaitu penelitian eksploratif.

Terdapat 17 prinsip yang akan menjadi acuan peneliti dalam melakukan wawancara. Dalam penentuan responden, peneliti ingin mendapatkan data dari responden yang memang memahami kondisi perusahaan dan bertugas untuk memanajemen perusahaan dan merupakan pimpinan yang bertanggung jawab langsung pada pengawas perusahaan. Sehingga teknik pengambilan sampel yang digunakan yaitu purposive sampling. Peneliti melakukan wawancara secara intens dengan responden sebanyak sebanyak 3 kali bertempat di kantor BPR X.

\section{PENGUMPULAN DAN PENGOLAHAN DATA}

\section{A. Responden}

Wawancara dilakukan kepada direksi dan manajer yang diperintah langsung oleh direksi selaku responden yang
Tabel 2.

Kondisi BPR X terhadap prinsip ke-5 manajemen risiko kredit BIS

\begin{tabular}{|c|c|c|}
\hline Prinsip & Kondisi Eksisting BPR & Status \\
\hline $\begin{array}{l}\text { Bank harus menetapkan } \\
\text { batas kredit secara } \\
\text { keseluruhan pada } \\
\text { tingkat peminjam } \\
\text { individual dan } \\
\text { counterparty }\end{array}$ & $\begin{array}{l}\text { - } \text { BPR X tidak } \\
\text { menetapkan batas } \\
\text { eksposur di segala } \\
\text { kegiatan. BPR X } \\
\text { mengatur batas }\end{array}$ & \\
\hline $\begin{array}{l}\text { Kriteria: } \\
\text { - } \text { Menetapkan batas } \\
\text { eksposur di segala } \\
\text { kegiatan yang } \\
\text { melibatkan risiko } \\
\text { kredit } \\
\text { - } \text { Bank } \\
\text { mempertimbang-kan } \\
\text { hasil stress testing } \\
\text { dalam setting limit } \\
\text { dan pemantauan } \\
\text { secara keseluruhan }\end{array}$ & $\begin{array}{l}\text { kewenangan } \\
\text { pencairan kredit } \\
\text { melalui aturan } \\
\text { internal BPR yang } \\
\text { disebut Batas } \\
\text { Wewenang } \\
\text { Memutus Kredit } \\
\text { (BWMK) } \\
\text { - BPR X tidak } \\
\text { melakukan stress } \\
\text { testing }\end{array}$ & $\begin{array}{c}\text { Tidak } \\
\text { Memenuhi }\end{array}$ \\
\hline
\end{tabular}

memenuhi kriteria yang telah ditetapkan. Hasilnya terdapat 1 orang direksi dan 3 orang manajer, atau di BPR X disebut dengan Pejabat Eksekutif (PE), yang manjabat pada saat dilakukan penelitian. Daftar responden tercantum dalam Tabel 1.

\section{B. Evaluasi Pelaksanaan Manajemen Risiko Kredit}

Peneliti mengacu pada ketujuh belas prinsip manajemen risiko kredit BIS. Peneliti mendapatkan data pengolahan dari hasil wawancara kepada responden terkait penerapan manajemen risiko kredit di PT BPR X. Peneliti melakukan evaluasi antara prinsip yang ada di Basel dengan keadaan BPR X. Panduan prinsip manajemen risiko kredit yang digunakan oleh penulis didapatkan di situs resmi BIS yaitu pada tautan http://www.bis.org/publ/bcbs75.htm. Ketujuh belas prinsip tersebut yaitu:

1. Dewan direksi harus bertanggung jawab untuk menyetujui dan melakukan peninjauan secara berkala terkait strategi risiko kredit dan kebijakan risiko kredit bank

2. Manajemen senior harus bertanggung jawab untuk menerapkan strategi risiko kredit yang disetujui oleh dewan direksi dan untuk mengembangkan kebijakan dan prosedur untuk mengidentifikasi, mengukur, memantau dan mengendalikan risiko kredit

3. Bank harus mengidentifikasi dan mengelola risiko kredit yang melekat pada semua produk dan aktivitas

4. Bank harus beroperasi dalam kriteria pemberian kredit yang jelas dan terdefinisi dengan baik

5. Bank harus menetapkan batas kredit secara keseluruhan pada tingkat peminjam individual dan counterparty

6. Bank harus memiliki proses yang jelas untuk menyetujui kredit baik kredit baru, amandemen, pembaruan dan pembiayaan kembali pada kredit yang telah ada

7. Semua perpanjangan kredit harus dilakukan secara arm's-length

8. Bank harus memiliki sistem untuk administrasi yang sedang berlangsung dari berbagai portofolio risiko kredit

9. Bank harus memiliki sistem pemantauan status kredit individu, termasuk menentukan kecukupan provisi dan cadangan

10. Bank didorong untuk mengembangkan dan memanfaatkan sistem penilaian risiko internal dalam mengelola risiko kredit 
Tabel 3

Kondisi BPR X terhadap prinsip ke-10 manajemen risiko kredit BIS

\begin{tabular}{|c|c|c|}
\hline Prinsip & Kondisi Eksisting BPR & Status \\
\hline $\begin{array}{l}\text { Bank didorong untuk } \\
\text { mengembangkan dan } \\
\text { memanfaatkan sistem } \\
\text { penilaian risiko internal } \\
\text { dalam mengelola risiko } \\
\text { kredit }\end{array}$ & \multirow[b]{2}{*}{$\begin{array}{l}\text { - BPR X tidak memiliki } \\
\text { sistem penilaian risiko } \\
\text { internal. Penilaian } \\
\text { hanya pada proses } \\
\text { analisis kredit, BPR X } \\
\text { membagi risiko } \\
\text { menjadi 3, yaitu risiko } \\
\text { rendah, risiko sedang } \\
\text { dan risiko tinggi } \\
\text { - Penilaian manajemen } \\
\text { risiko BPR X } \\
\text { mengacu pada } \\
\text { ketentuan OJK }\end{array}$} & \multirow[b]{2}{*}{$\begin{array}{c}\text { Tidak } \\
\text { Memenuhi }\end{array}$} \\
\hline $\begin{array}{l}\text { Kriteria: } \\
\text { - } \text { Memiliki sistem } \\
\text { penilaian risiko internal } \\
\text { dalam mengelola risiko } \\
\text { kredit } \\
\text { - } \\
\text { Sistem penilaian risiko } \\
\text { internal bank harus } \\
\text { responsif terhadap } \\
\text { indikator potensi atau } \\
\text { penurunan yang } \\
\text { sebenarnya dalam } \\
\text { risiko kredit } \\
\text { - Melakukan peninjauan } \\
\text { dan pembaruan } \\
\text { terhadap penilaian atau } \\
\text { pemeringkatan debitur } \\
\text { secara periodik }\end{array}$ & & \\
\hline
\end{tabular}

11. Bank harus memiliki sistem informasi dan teknik analisis yang memungkinkan manajemen untuk mengukur risiko kredit yang melekat pada semua aktivitas neraca

12. Bank harus memiliki sistem pemantauan keseluruhan komposisi dan kualitas portofolio kredit

13. Bank harus mempertimbangkan perubahan kondisi ekonomi di masa depan dalam menilai kredit individu maupun portofolio kredit, juga harus menilai eksposur risiko kredit dalam kondisi penuh tekanan

14. Bank harus menetapkan sistem penilaian manajemen risiko kredit yang independen dan berkelanjutan dan hasil review tersebut harus disampaikan secara langsung kepada dewan direksi dan manajemen senior

15. Bank harus memastikan bahwa fungsi pemberian kredit dikelola dengan baik dan eksposur kredit berada dalam tingkat yang konsisten dengan standar kehati-hatian dan batasan internal.

16. Bank harus memiliki sistem yang berlaku untuk tindakan perbaikan awal pada memburuknya kredit, mengelola kredit bermasalah dan situasi serupa

17. Pengawas harus mewajibkan bank memiliki sistem yang efektif untuk mengidentifikasi, mengukur, memantau dan mengendalikan risiko kredit sebagai bagian dari keseluruhan pendekatan manajemen risiko

Peneliti menggunakan prinsip-prinsip BIS sebagai panduan dalam pertanyaan wawancara. Pada tiap prinsip peneliti membagi kembali menjadi beberapa kriteria yang akan dievaluasi terhadap kondisi eksisting PT BPR X. Hasil dari wawancara dan observasi terkait penerapan manajemen risiko kredit yaitu 14 dari 17 prinsip telah terpenuhi oleh PT BPR X.

BPR X dapat memenuhi prinsip ke-1 hingga ke-4. Kondisi BPR X terhadap prinsip ke-5 manajemen risiko kredit BIS berstatus tidak memenuhi dikarenakan kriteriakriteria yang ada pada prinsip tersebut tidak ada seperti yang tercantum dalam Tabel 2.

Prinsip ke-6 hingga prinsip ke-9 dapat terpenuhi oleh BPR X. Pada prinsip ke-10, BPR X tidak memenuhi prinsip
Tabel 4

Kondisi BPR X terhadap prinsip ke-13 manajemen risiko kredit BIS

\begin{tabular}{lll}
\hline \hline \multicolumn{1}{c}{ Prinsip } & $\begin{array}{l}\text { Kondisi Eksisting } \\
\text { BPR }\end{array}$ & Status \\
\hline $\begin{array}{l}\text { Bank harus mempertimbangkan } \\
\text { perubahan kondisi ekonomi di } \\
\text { masa depan dalam menilai } \\
\text { kredit individu maupun } \\
\text { portofolio kredit, juga harus } \\
\text { menilai eksposur risiko kredit } \\
\text { dalam kondisi penuh tekanan }\end{array}$ & $\begin{array}{l}\text { BPR X tidak } \\
\text { melakukan } \\
\text { analisis skenario } \\
\text { dan stress testing }\end{array}$ & \\
\hline - $\begin{array}{l}\text { kepada } \\
\text { debiturnya. BPR } \\
\text { skenario dan stress testing }\end{array}$ & $\begin{array}{l}\text { X melakukan } \\
\text { analisis khusus }\end{array}$ & Memenuhi \\
- Bank melakukan peninjauan & pada kondisi- \\
kondisut dari stress testing & debitur & \\
\hline \hline
\end{tabular}

tersebut dikarenakan tidak terlaksananya kriteria yang ada. Seperti yang tercantum pada Tabel 3.

Prinsip ke-11, prinsip ke-12, prinsip ke 14 hingga ke-17 memenuhi prinsip BIS. Sedangkan prinsip ke-13 kondisi eksisting BPR X tidak memenuhi kriteria-kriteria pada prinsip ke-13 BIS tersebut seperti yang tertera pada Tabel 4.

\section{ANALISIS DAN DISKUSI}

\section{A. Analisis Prinsip Manajemen Risiko Kredit}

Dari ketujuh belas prinsip manajemen risiko kredit BIS, terdapat 3 prinsip yang berstatus tidak memenuhi. Ketiga prinsip tersebut yaitu prinsip ke-5, prinsip ke-10, dan prinsip ke-13.

Prinsip ke-5 membahas tentang batas kredit. Prinsip ke-5 berstatus tidak memenuhi dikarenakan BPR tidak memiliki kebijakan terkait batas eksposur risiko kredit. BPR X hanya memberikan batas kredit bagi pemberi kewenangan kredit yaitu pimpinan berupa Batas Wewenang Memutus Kredit (BWMK). BPR X mengkategorikan menjadi 3 batas wewenang untuk tiga level pimpinan. BPR X menetapkan bahwa batas kewenangan bagi Kabag Kredit BPR X sebesar 7,5 juta rupiah. Batas kewenangan bagi direktur sebesar maksimal 20 juta rupiah. Dan batas kewenangan bagi direktur utama yaitu sebesar maksimal 75 juta rupiah. Apabila diatas 75 juta rupiah, maka kewenangan adalah milik komisaris. BPR tidak menetapkan batas kredit pada tingkat peminjam individual maupun lainnya. Bank juga tidak melakukan stress testing kepada seluruh calon debitur. Namun BPR X melakukan penilaian terhadap laporan arus kas calon debitur apabila dirasa perlu untuk kepentingan analisis.

Prinsip ke-10 membahas tentang sistem penilaian risiko internal. Prinsip ke-10 berstatus tidak memenuhi dikarenakan BPR tidak memiliki sistem penilaian risiko internal. Sistem penilaian manajemen risiko yang dimiliki oleh BPR X mengacu pada OJK. Sehingga tidak ada pengembangan lebih lanjut terkait penilaian risiko internal.

Prinsip ke-13 membahas tentang analisis skenario untuk stress testing. Prinsip ke-13 berstatus tidak memenuhi dikarenakan tidak adanya penilaian mendatang untuk kondisi dalam tekanan (stress). BPR hanya melakukan penilaian mendatang untuk pemenuhan kewajiban debitur. BPR X tidak melakukan analisis skenario stress testing kepada seluruh nasabah. Sehingga bank tidak memiliki data simulasi terkait kondisi terburuk yang dapat dialami oleh debitur ketika melaksanakan kewajibannya. 


\section{B. Implikasi Manajerial}

Dari hasil analisis yang dilakukan peneliti didapatkan hasil bahwa sebuah BPR yang notabene peraturan dan kebijakan yang diatur pemerintah tidak seketat pada bank umum, namun dapat memenuhi prinsip-prinsip manajemen risiko kredit BIS dengan baik. Dari ketujuh belas prinsip manajemen risiko kredit, BPR X telah memenuhi 14 prinsip. Hal-hal dasar terkait penerapan manajemen risiko kredit berpedoman pada peraturan OJK nomor 13/POJK.03/2015 dan peraturan BI juga telah terlaksana dengan baik oleh BPR X. Pengembangan-pengembangan secara internal BPR tentu akan berdampak pada kemajuan BPR.

Mulai per Desember 2014 berdasarkan laporan publikasi BPR X, modal dasar yang dimiliki yaitu sebesar 20 miliar rupiah, dengan modal disetor sebesar 5 miliar rupiah dan modal inti BPR X yang sebesar 7,82 miliar rupiah. Dari sisi permodalan, membuktikan bahwa BPR $X$ ini memiliki potensi yang besar untuk berkembang lebih maju lagi. Potensi besar ini harus didukung dengan manajemen risiko kredit yang semakin kompleks pula. Sistem penilaian risiko internal sebagai pendukung pengelolaan manajemen risiko dapat diterapkan pada BPR X, mengingat BPR X belum memiliki sistem ini. Apabila sistem penilaian risiko internal telah dibuat, BPR dapat meningkatkan kegiatan peninjauan kepada nasabah. Selain itu hasil dari penilaian risiko internal juga dapat digunakan sebagai bahan evaluasi penanggung jawab kredit, mulai dari account officer hingga direksi. Apabila hasil penilaian risiko baik, maka analisis kredit yang dilakukan juga sudah baik, karena penilaian risiko merupakan cerminan hasil dari analisis kredit yang dilakukan untuk menyeleksi calon debitur yang memang layak untuk diberi kredit. Sehingga penilaian risiko kredit internal dimulai dari segala informasi tentang debitur.

\section{KESIMPULAN}

Hasil penerapan manajemen risiko kredit BPR X dianalisis menggunakan prinsip-prinsip manajemen risiko kredit Bank of International Settlements (BIS) yaitu BPR X memenuhi 14 dari 17 prinsip yang dibuat oleh BCBS. Terdapat 3 prinsip yang tidak memenuhi yaitu pertama prinsip kelima yang membahas terkait penetapan batas kredit secara keseluruhan pada tingkat peminjam individual dan counterparty. Prinsip yang tidak memenuhi kedua adalah prinsip kesepuluh yang membahas mengenai pengembangan dan pemanfaatan sistem penilaian risiko internal dalam mengelola risiko kredit bank. Dan prinsip yang tidak memenuhi ketiga yaitu prinsip ketiga belas yang membahas bahwa bank harus mempertimbangkan perubahan kondisi ekonomi di masa depan dalam menilai kredit individu maupun portofolio kredit, juga harus menilai eksposur risiko kredit dalam kondisi penuh tekanan (stress).

\section{DAFTAR PUSTAKA}

[1] Otoritas Jasa Keuangan, "Statistik Perbankan Indonesia," Jakarta, 2016.

[2] D. Idat, "Mencermati Daya Saing BPR," Republika, 16-Nov2016.

[3] Apriyani, "BPR Ditutup, Lagi-lagi Karena Fraud," 2016 [Online]. Available: http://infobanknews.com/bpr-ditutup-lagilagi-karena-fraud/. [Accessed: 22-Mar-2017].

[4] Apriyani, “April 2015, NPL Melonjak Tajam,” 2015. [Online] Available: http://infobanknews.com/april-2015-npl-kreditmelonjak-tajam/. [Accessed: 22-Mar-2016].

[5] Bank for International Settlements, "Assessment of Basel III riskbased capital regulation - Indonesia," Indonesia, 2016.

[6] R. H. Clough and G. A. Sears, Construction Contracting, 6th ed New York: John Wiley \& Sons Inc, 1994.

[7] D. C. Pushner and S. Bouteille, The Handbook of Credit Risk Management: Originating, Assessing, and Managing Credit Exposures. New York: John Wiley \& Sons Inc, 2013.

[8] W. Djohan, Kredit Bank, 1st ed. Jakarta: PT. Mutiara Sumber Widya, 2000. 